\title{
Impact of digital technologies on the company's business model
}

\author{
Tatyana Averina ${ }^{1, *}$, Sergey Barkalov ${ }^{1}$, Irina Fedorova $^{1}$, and Vera Poryadina $^{1}$ \\ ${ }^{1}$ Voronezh State Technical University, Moscow Avenue, 14, Voronezh, 394026, Russia
}

\begin{abstract}
The fourth industrial revolution is destroying traditional business models of companies. In order to maintain the current level of competitiveness, companies must adapt to changing conditions, draw up and implement strategies for introducing digital technologies into their business processes. The article presents a structured approach for systematic modeling of business digitalization.
\end{abstract}

\section{Introduction}

\subsection{Digitalization}

The fourth industrial revolution Industry 4.0 is associated with the digitalization of all company management processes. At the same time, traditional business processes are being destroyed, due to the fact that new technologies give a competitive advantage to those who have mastered their use - technological market leaders. The article presents a methodology for digital transformation of business models of companies. Digital technology is changing the way value is created as well as the outcome of innovation. For example, by attaching sensors to industrial equipment, engineers can create a digital twin and then use it to identify drawbacks in the current design or operation of equipment [1-4]. In this case, digital technologies act as tools that open up new lines of innovation. On the other hand, digital innovations can be new service systems (services) for pre-existing products, such as smart watches. The sensors built into the watch generate digital data to help people determine their heart rate, physical activity and track their performance.

Digital technologies are also changing the way a company interacts with customers and partners, transforming internal processes and opening up opportunities for identifying and implementing new methods of distributing products and opportunities for monetizing services.

Here are three examples where digitalization destroys existing business models:

- a new entrant - often a startup that enters an existing market and offers an innovative value proposition;

- a traditional competitor in your industry changes its business model and becomes a much more serious competitor. For example, according to "Data Insight" analysts, the Utkonos retailer in April 2020 for the first time in 13 years lost its leadership in the Russian online

\footnotetext{
${ }^{*}$ Corresponding author: ta_averina@mail.ru
} 
food sales market to X5 Retail Group. Sales through the launched services Perekrestok.ru and Dostavka.Pyaterochka reached 1.7 billion rubles, which is 4.7 times more than a year earlier;

- a company in another industry expands its business boundaries and enters your market. So, in an interview with "Kommersant", the president of the credit institution, German Gref, said that the non-financial digital business in 2019 brought Sber 35 billion rubles. One of the goals of Sber's 2020 strategy is to implement initiatives to compete with global tech companies. So, on June 17, 2020, Sber announced the launch of the multifunctional service SberZdorovye, which will provide a range of medical services.

Products and processes that used to be physical are now digital [5-7]. Previously, newspapers were printed at night in a printing house and then transported by freight transport for sale at newsstands and shops. Now news is presented in digital format and spread throughout the world in literally seconds. Likewise, internal processes in companies were once heavily dependent on paper document flow, and now digital technologies allow remote interaction and other social processes, speeding up decision-making and saving time [8-10]. Almost everything can now be digitized by receiving digital data, for example, using sensors. Further processing of this data can generate valuable additional information. Typically, the following data types are used for this:

- social data. For example, tweets and facebook posts can be tracked to understand brand attitudes - positive or negative;

- customer data. They can be used to understand customer behavior and characteristics, which can then improve the presentation of the product to the target audience;

- sensor data - can help improve logistics, infrastructure management, help design smart cities and model new ways of working;

- interactive data: if we are talking about smart cities, understanding where people are going, how they move around the city, can help optimize planning and design.

\subsection{Examples of digital business models}

Digital platforms

Platforms like Uber work globally around the world and use the capabilities of mobile devices and applications to connect customers with service providers. The analysis of the platform business lines is shown in Table 1.

Table 1. Analysis of Uber business lines

\begin{tabular}{|c|c|l|}
\hline Business line & $\begin{array}{c}\text { Service } \\
\text { name }\end{array}$ & \multicolumn{1}{|c|}{ Description of the service } \\
\hline Travel booking & UberX & $\begin{array}{l}\text { Order a taxi with a driver registered in the } \\
\text { corresponding Uber application. }\end{array}$ \\
\cline { 2 - 4 } & Uber Pool & $\begin{array}{l}\text { Shared rides, door-to-door or with short-stop rides with } \\
\text { a driver registered in the corresponding Uber } \\
\text { application. }\end{array}$ \\
\hline & $\begin{array}{c}\text { Uber } \\
\text { Comfort }\end{array}$ & Ordering newer comfortable cars as a taxi. \\
\hline Food delivery & Uber Eats & $\begin{array}{l}\text { Ordering food from a restaurants that have posted their } \\
\text { offers in the appropriate Uber application. }\end{array}$ \\
\hline
\end{tabular}




\begin{tabular}{|c|c|c|}
\hline $\begin{array}{l}\text { Transportation to } \\
\text { medical institutions }\end{array}$ & Uber Health & $\begin{array}{l}\text { Ordering medical transport to transport patients to or } \\
\text { from the place where the necessary medical services are } \\
\text { provided. Transportation is provided by medical } \\
\text { organizations that have registered in the corresponding } \\
\text { Uber application. }\end{array}$ \\
\hline $\begin{array}{l}\text { Integrated solutions } \\
\text { to improve the } \\
\text { operation of urban } \\
\text { public transport, } \\
\text { logistics solutions for } \\
\text { small companies }\end{array}$ & Uber Transit & $\begin{array}{l}\text { Organization of a payment system through the Uber } \\
\text { application, services for the formation of a trip route on } \\
\text { city public transport. } \\
\text { Providing Uber's network and technology so that small } \\
\text { businesses can offer door-to-door services at less cost } \\
\text { than building and implementing their own solutions. } \\
\text { For example, in some cities, Uber allows users to build } \\
\text { walking routes and makes it easier to plan a trip using } \\
\text { different kinds of transport. }\end{array}$ \\
\hline \multirow[t]{2}{*}{ Offers for companies } & Uber Freight & $\begin{array}{l}\text { In the Uber app, you can select carriers and shippers. } \\
\text { Shippers place an order for the goods they want to } \\
\text { transport, and the carriers immediately know how much } \\
\text { they will be paid. }\end{array}$ \\
\hline & $\begin{array}{l}\text { Uber for } \\
\text { Business }\end{array}$ & $\begin{array}{l}\text { Uber enables you to manage your company's ground } \\
\text { transportation needs. For example, it is possible to } \\
\text { control short-term business trips of employees based on } \\
\text { automatically issued invoices, cost accounting and } \\
\text { reporting. }\end{array}$ \\
\hline $\begin{array}{l}\text { Advanced } \\
\text { transportation } \\
\text { technology }\end{array}$ & $\begin{array}{l}\text { Advanced } \\
\text { Technologies } \\
\text { Group }\end{array}$ & $\begin{array}{l}\text { Implementation of the possibility of ordering unmanned } \\
\text { vehicles in the Uber network. }\end{array}$ \\
\hline $\begin{array}{l}\text { Development of air } \\
\text { transportation }\end{array}$ & Uber Air & $\begin{array}{l}\text { Uber is developing a share air transportation service } \\
\text { with plans to open in 2023. It is designed to move } \\
\text { between suburbs and cities. Uber is working to launch a } \\
\text { fleet of small electric vertical take-off and landing } \\
\text { aircraft in Dallas, Los Angeles and Melbourne. }\end{array}$ \\
\hline
\end{tabular}

Open digital models

Another open source business model is WordPress. WordPress can be used for free by those who have enough basic functionality or those who have specialists who are able to customize or program the necessary features for the company. For those looking for a simpler solution, however, there is a premium ready-to-use subscription-based solution on WordPress.com with additional useful features.

E-commerce

Online retailers like Amazon have changed the way we shop. In addition, Amazon uses artificial intelligence and machine learning to generate personalized offers in the purchase selection process. Without digital technology, Amazon's entire supply chain would disintegrate.

\section{Methodology for developing and improving the digitalization of a business model}

Every industry has technology leaders who have already digitally transformed their businesses. Consumers, using their services, have time to get used to the convenient interface of information resources and mobile applications, the presence of a website and an online chat, the ability to quickly place an order and track the process of its packaging, assembly 
and delivery in real time, and get quick feedback. It has already become the norm to minimize the need to visit an office (store) when submitting a service request, ordering goods, processing a request to provide access to information or some kind of digital resource. At the same time, consumers' expectations in relation to other companies on the market naturally grow, even if they operate in a different industry and market segment.

Consumers value their time, want to receive services quickly and conveniently, and expect companies to satisfy their needs. To do this, companies need to accelerate the digitalization of their business processes.

Every company that is going to change its business model to digital must first have a strategy that will guide the analysis and change of the current business model.

There are three groups of strategic directions for digital transformation of the business model:

- operational and technological excellence (shifting focus to improving the efficiency of the value chain and the introduction of new production technologies);

- excellence in solutions for clients (shifting focus to the formation of a high level of products and services provided);

- $\quad$ proximity to the customer (shifting focus to presenting value to the customer).

When digitalizing business processes, people remain the center of the transformation strategy. Decisions need to be assessed in terms of how they affect the company's customers, employees, business partners, society, or other key groups. You need to know the key target groups for the company and how they interact with the company. Digital technologies are opening up new forms of interaction, so creative vision and thinking are needed to innovate. For the digital transformation of a business model, it is not enough to limit ourselves to the introduction of modern information technologies and the automation of existing business processes. This will ensure the implementation of the company's processes on the basis of modern information technologies, but will give it little for the growth of competitiveness [1112]. A company needs to creatively analyze existing business processes and essentially redesign them in an attempt to achieve the following goals:

- reduction of the execution time of the decision-making loop;

- orientation of business processes to the characteristics and needs of their consumers;

- reduction in the number of employees involved in each business process.

To facilitate the digital transformation of the business process, the authors of the article propose to use the following 5-step algorithm (A1):

Step 1. Assessment of the digital maturity of the company.

Does the company have separate divisions that have invested in innovative digital solutions and redesigned their business processes, discarded their ineffective parts?

If the answer is yes, then go to Step 4. Otherwise, we answer the following question: are the main business processes (the "basis" of digital transformation) automated?

If the answer is yes, then go to Step 3, otherwise go to Step 2.

Step 2. Automation of working business processes, introduction of a new culture of interaction between employees with a focus on the use of automation tools.

Step 3. If the company is ready to digitally transform all its business processes at once (and this is costly, both in terms of finances and in terms of time), then go to Step 4.

We select the divisions of the company whose business processes will be transformed. We buy suitable digital solutions or switch to using the standards of existing electronic platforms. We redesign the business processes of these divisions, excluding ineffective parts and redundant employees.

Step 4. Digital transformation of all business processes of the company is carried out. 
This is a rather lengthy process for which someone should be responsible. Therefore, a digital transformation unit is being created, the head of which must control the process.

All business processes of the company are redesigned, taking into account the needs of consumers, obtained on the basis of business analytics, intelligent marketing opportunities and the implementation of self-service capabilities in business processes.

To facilitate this step, in any order and even cyclically, the following concepts can be used:

- consideration of digital business model templates to develop some initial ideas for business digitalization. Selecting of specific templates for further analysis;

- choosing a strategic direction, developing ideas for digital transformation and optimizing them with regard to cost;

- explaining how digital technology is being used to drive business model ideas and create value.

Step 5. Digital transformation of the business model is carried out in all branches of the company, if any.

When analyzing and redesigning existing business processes, it is important not to focus only on their automation, which can lead to the reproduction of all existing shortcomings and bottlenecks. For this, it is proposed to use the following algorithm (A2):

Step 1. Formulate a plan to automate the traditional business process - what you will automate and based on what technologies and solutions. Draw a diagram of an automated business process.

Step 2. Try to exclude some participants in the business process or replace them with the help of modern information technologies.

Step 3. Check to see if part of the business process can be supplemented with a selfservice alternative.

Step 4. Check if, in addition to the business process, you can create an alternative business process for the consumer that is implemented as self-service.

Step 5. Decide if you need automated business processes for which alternative self-service business processes have been created.

To further improve and refine the digital business model, the design of services or business processes of the company is carried out on the basis of the most common and effective methodology "design thinking" [13-16].

The application of this methodology consists of the following steps [17]:

- stage 1 - research of target customers of the company and their needs;

- stage 2 - creation of typical characters, base consumer journey maps and service blueprints - determination of their points of interaction;

- stage 3 - development of new service ideas;

- stage 4 - rapid prototyping of a new service, definition of new consumer journey maps and service blueprints;

- stage 5 - testing the new service for feasibility, desirability and viability.

Let's consider stages 1-3 in more detail.

\subsection{Research of target customers of the company and their needs}

The study of the company's target customers and their needs is carried out on the assumption that after going through the digital transformation of the business model, the company has its own website with a personal account for users and the ability to choose electronic services offered by the company.

In this case, you can use the digital Google Marketing Platform. 
This platform includes two very convenient digital tools - Google Analytics and Google Tag Manager. Google Analytics service allows you to collect information about the marketing promotion of company products. Google Tag Manager allows you to generate tracking counters and embed them on a company's website. This allows you to find out how the user interacted with the site and electronic services. This information allows the formation of users digital profiles that reflect their preferences and the way they work with the company's services.

In the absence of a website, the company can collect information about its consumers based on the interview method.

\subsection{Create typical characters, customer journey maps, and service blueprints}

Creation of typical characters

Service design requires a deep understanding of the explicit and implicit needs of their customers. Each service is addressed to more than one consumer and even possibly more than one segment of consumers, but to understand how it meets the needs of consumers, it is necessary to develop a very specific Character that reflects the person who will use this service. It is best to design at least one character for each customer segment.

The Character description should be as accurate and detailed as possible, providing the designers with enough detail to understand how the Character interacts with a particular digital function.

Creation of customer journey maps

Customer journey maps are models that show the stages that target characters go through to complete a task or complete a process. Customer journey maps, for example, show the steps a customer goes through to purchase products, contact customer support, or complain about the company on social networks.

Consumer journey maps typically contain the following main components:

- definition of your client

First of all, you need to formulate a commercial goal for the achievement of which a customer map is drawn up.

Here are some examples of business goals that can be achieved with mapping:

create a template path that can be applied to all or nearly all customers, and that can be used to create a common understanding among company employees for each stage of the buying cycle, including points of interaction with customers;

implementation of a new customer segmentation scheme or optimization of the sales process for a priority group of customers;

expanding your business by working with new clients or with a segment of clients that you have not fully engaged in before.

Linking a customer journey map to a specific customer character helps establish and maintain a common understanding of the ideal customers and how they interact with the company.

- creating a customer journey map from the buyer's perspective

A customer journey map is built according to their stages of the buying process, representing the customers journey towards achieving their goals. The map should not be focused on the stages of the company's internal processes.

Each stage represents a meaningful goal that the customer is trying to achieve as they move along the journey.

- identifying the goals of the company's clients

Clients interact with the company's brand to achieve their goals (desires, expectations).

Examples of client goals:

I want to know the possible alternatives; 
I want to be sure the price is fair;

I want to feel respected.

By clearly defining the customer's goals at each stage of the journey, you can assess how the customer experience provided by the company contributes to the achievement of the customer's goals.

- description of the points of contact between the client and the company

Points of contact are points of interaction between a client and a company using tools or resources, or vice versa - the lack of interaction. More often than not, the value of customer journey maps lies in clearly understanding the points of interaction with the company along the entire customer journey.

You need to understand that for points of interaction to become part of a real shopping experience, you need a real customer to use them on the way to their goal.

- using a journey map to convey client emotions

It is critical to capture the emotions of customers all the way to gain real insight into their experience. It is also very important to understand the difference between what the client of the company wants to feel at each stage of his journey, and how he actually feels.

To retain your customers and attract new ones, you need to provide the client with a memorable positive experience that he wants to repeat.

In the map you can use words, phrases, icons, and other visual aids to represent the customer's feelings in a quality manner along the way. In the maps that measure emotions you can use scores, tables, and graphs.

- collecting data on how customers evaluate their own experience

Customer journey mapping projects should always include customer assessment of their experience.

You can use the following assessment types:

- emotional assessment;

- the importance of the interaction point, tool or resource;

- satisfaction with an interaction point, tool or resource;

- satisfaction with the amount of time it took to reach the goal.

Some maps use a visual approach to convey information about obstacles and good points along the customer journey - signs that clearly mark them as pain points and delight points.

- implementation of innovations taking into account growth opportunities

The main goal of almost all customer journey mapping projects is to increase the number of customers by improving the shopping experience. Therefore, the customer's map should become a tool for planning the company's development.

A map can help you see growth opportunities, assess their value, and identify which investments are top priorities for the company.

- reflection of internal resources and processes responsible for creating a shopping experience in the map

It is a look at building a customer map from the inside out - mapping the internal systems, processes and people involved in creating a journey.

- consideration of thinking - voiced (and not voiced) thoughts of the client

Some maps contain the category of thinking. If you know the goals of the company's customers at each stage of the journey, then most likely it will be possible to include the thinking item in the map.

This item is often combined with actions and feelings on customer journey maps. This model shows what the customer is thinking about, as well as his actions and how he feels while doing these actions. Many maps include all three of these categories - although they are not always ordered exactly that way or are also called.

\section{Service blueprint}


When developing a service blueprint, it is necessary to describe its main elements, which are presented in Table 2 .

Table 2. Elements of the service blueprint

\begin{tabular}{|c|l|}
\hline \multicolumn{1}{|c|}{ Name } & \multicolumn{1}{|c|}{ Short description } \\
\hline Frontstage actions & $\begin{array}{l}\text { These are actions that take place directly in front } \\
\text { of the consumer's eyes. } \\
\text { If a consumer journey has already been mapped, } \\
\text { then it is possible to highlight the steps, actions } \\
\text { and interactions that the consumer must go } \\
\text { through to achieve their goals. } \\
\text { For example, a consumer interacts with a cashier } \\
\text { when paying for their purchases or with a } \\
\text { machine when paying for services through an } \\
\text { ATM. }\end{array}$ \\
\hline Backstage actions & $\begin{array}{l}\text { These are actions that are performed by service } \\
\text { employees and which are "invisible" to the } \\
\text { consumer. For example, when a consumer } \\
\text { chooses and orders a bouquet online, the florist } \\
\text { composes it, and the ordering clerk sends it to } \\
\text { the delivery service. }\end{array}$ \\
\hline Support processes & $\begin{array}{l}\text { It is a set of steps and interactions that enable } \\
\text { service employees to deliver services to their } \\
\text { customers. } \\
\text { In this case, interactions can be performed both } \\
\text { between different divisions of the same } \\
\text { company, and with external services. }\end{array}$ \\
\hline Physical evidences & $\begin{array}{l}\text { The physical evidences are tangible proofs that } \\
\text { the interaction between the service and the } \\
\text { consumer actually happened. For example, this } \\
\text { is the product purchased itself, a receipt or } \\
\text { check confirming the purchase, etc. }\end{array}$ \\
\hline & \begin{tabular}{c} 
cons \\
\hline
\end{tabular} \\
\hline
\end{tabular}

The service blueprint is usually divided into parts by three main lines that reflect:

- line of interaction: represents all direct interactions between the consumer and the company;

- line of visibility: separates the visible and the invisible to the customer - the visible is above the line, and everything else is below the line;

- line of internal interaction: divides employees into those who directly work with clients, and those who are not directly involved in interaction with clients. Depending on the subject area in which the company operates, as well as its business goals, the following parts of the service blueprint can also be added:

- time. If the service provided has strict time limits, then the service blueprint should track how long each action and interaction takes;

- regulations. To improve the quality of the services provided, you can introduce rules that do not violate the law for employees and consumers, which will regulate the procedure for resolving problems and claims;

- evaluation metrics. If the goal is to optimize operating costs, then you need to collect data on the operation of the service and visually show how, where, and how much time and money is spent. 
An example of a service blueprint template is shown in Figure 1.

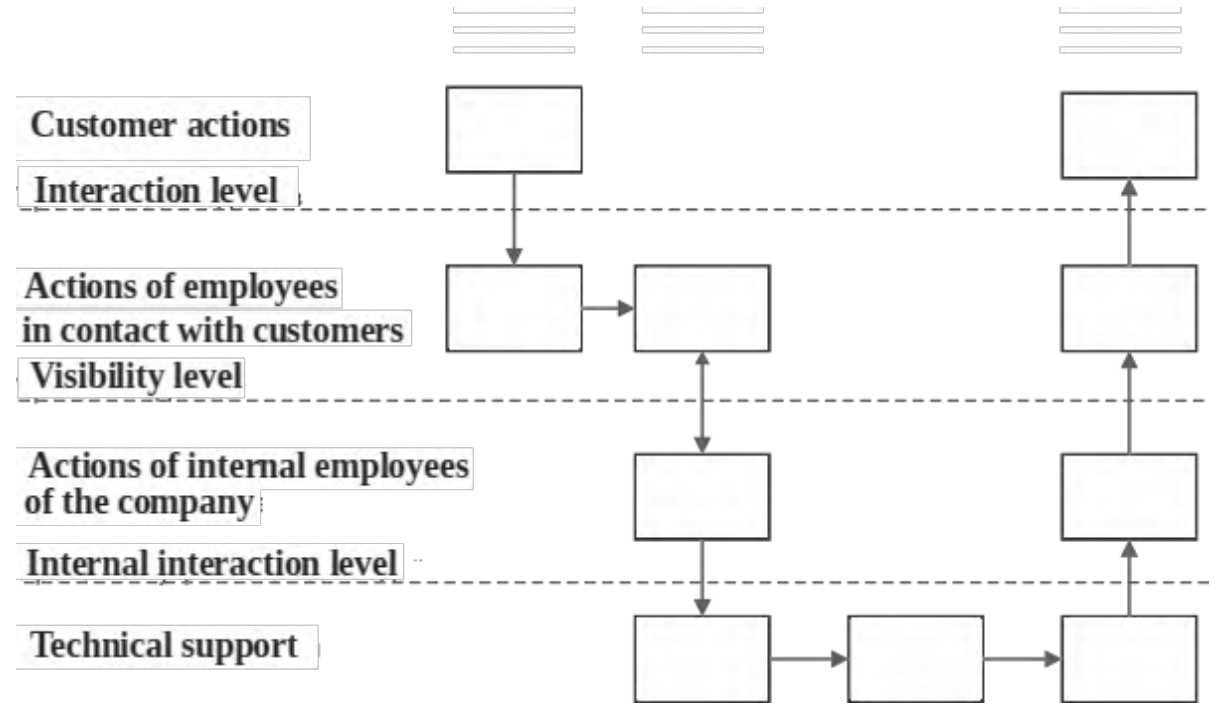

Fig. 1. Service blueprint template

\subsection{Developing new service ideas}

The digital transformation of a company's business model is an ongoing process. Therefore, it is necessary to monitor the business models of competitors to identify innovations that can be implemented in the company.

It is also necessary to keep an eye on new digital technologies, paying attention to the opportunities for their application to improve the quality of customer service or create new valuable products for the consumer.

\section{Conclusions}

In response to the challenges of the digital economy, we need not only tools for the development of digital technologies; but also a methodology for systematic digital business modeling. The structured approach that we presented in this article is one step in this direction. However, more research and practice is needed. A feature of Russian business is that many companies associate digitalization only with the introduction of technological innovations and the development of information technologies, although digital transformation is a complex transformation that affects all processes of organizing and doing business. Therefore, further research is required to build methodologies that allow, depending on the needs of the business and the strategic priorities of the company, given its digital maturity, to select the appropriate technologies and digital value creation factors that will allow the company to successfully execute digital business transformation.

\section{References}

1. A. Burger, "IDC: Internet of Things Base to Reach 30 Billion in 2020," Telecompetitor, November 7 (2014)

2. "Internet-Of-Things Software Platforms Simplify Transformation Of Business Operations," Forrester Research, Inc., April 2 (2015) 
3. "Vendor Landscape: Container Solutions For Cloud-Native Applications," Forrester Research, Inc., January 30 (2017)

4. "Architect Hybrid Cloud Management To Boost Your Digital Business," Forrester Research, Inc., August 25 (2015)

5. Imagining the Digital Future: How Digital Themes Are Transforming Companies Across Industries, EY Research Report, February, 7 (2015)

6. J. Lopez, Gartner, Inc., "Digital Business is Everyone's Business," Forbes, May 7 (2014)

7. P. P. Kumari, M. Shalini, Prasad KDV Yarlagadda, "Digital ManufacturingApplications Past, Current, and Future Trends", Procedia Engineering, 174, 982 - 991 (2017)

8. D. Schallmo, C. A. Willams, Boardman Luke "Digital Transformation of Business Models-Best Practice, Enabler, and Roadmap", International Journal of Innovation Management, 21(8), (December 2017) 1740014-17 (2018)

9. C. Pelletier, L. M. Cloutier, "Challenges of Digital Transformation in SMEs: Exploration of IT-Related Perceptions in a Service Ecosystem", Proceedings of the 52nd Hawaii International Conference on System Sciences, 4967-4976 (2019)

10. B. Barann, A.-K. Cordes, A. Hermann, F. Chasin, "Supporting Digital Transformation in Small and Medium-sized Enterprises: A Procedure Model Involving Publicly Funded Support Units" Proceedings of the 52nd Hawaii International Conference on System Sciences, 4977-4986 (2019)

11. V. Poryadina, V. Burkov, S. Barkalov, I. Ilin, O. Kalinina, Competitive Mechanisms of the Functioning of Social and Economic Systems, MATEC Web of Conferences conference proceedings, 01122 (2018)

12. T. Averina, E. Avdeeva, O. Perevalova, Introduction of Management Innovations in the Work of Municipal Organizations, MATEC Web of Conferences, 170, 01121 (2018)

13. T. von Leipzig, M. Gampa, D. Manz, K. Schöttle, P. Ohlhausena,c, G. Oosthuizenb, D. Palma, K. von Leipzig, "Initialising customer-orientated digital transformation in enterprises", Procedia Manufacturing, 8, 517 - 524 (2017)

14. A. Bonakdar, O. Gassmann, Design Thinking for Revolutionizing Your Business Models, Design Thinking for Innovation. Research and Practice, 1 st edn, 57-66 (New York: Springer, 2016)

15. F. Darbellay, Z. Moody, T. Lubart, Creativity, Design Thinking and Interdisciplinarity, 1 st edn., 214 (Singapore: Springer Nature, 2017)

16. M. A. Pfannstiel, C. Rasche, Service Design and Service Thinking in Healthcare and Hospital Management, 535 (Cham: Springer, Switzerland, 2019)

17. H. Plattner, Ch. Meinel, L. Leifer, Design Thinking Research. Building Innovator, 1 st edn., 286 (New York: Springer) doi: 10.1007/978-3-319-06823-7 (2015) 